\title{
Activation of Heterophils and Monocytes in Chicken with a Formulation Containing a Seaweed Extract from Ulva armoricana
}

\author{
Guriec $\mathbf{N}^{1}$, Bussy $\mathrm{F}^{2,4 *}$, Gouin $\mathrm{C}^{2,4}$, Mathiaud $\mathbf{0}^{3}$, Le Goff $\mathbf{M}^{2,4}$, Delarue $\mathrm{J}^{1}$ and \\ Nyvall Collén $\mathrm{P}^{2,4}$ \\ ${ }^{1}$ Department of nutritional sciences, University Hospital, Faculty of medicine, University of \\ Brest, France \\ ${ }^{2}$ Amadeite SAS, France \\ ${ }^{3}$ R\&D Breizh, France \\ ${ }^{4}$ Olmix SA, France
}

\section{Research Article \\ Volume 6 Issue 1}

Received Date: March 11, 2021

Published Date: April 07, 2021

DOI: $10.23880 /$ oajvsr-16000208

*Corresponding author: Bussy F, Olmix SA, ZA du Haut du Bois, 56580 Bréhan, France, Tel: +33 7864770 40; Email: fbussy@ olmix.com

\section{Abstract}

Responsiveness to invasive pathogens, clearance via the inflammatory response, and activation of appropriate acquired responses are all coordinated by innate host defenses. We have previously demonstrated that a purified ulvan extract of Ulva armoricana is able to activate avian heterophils and monocytes in vitro and in vivo, leading to in vivo release of cytokines including interleukin $1 \beta$ (IL1 $\beta$ ), interferon $\alpha$ (IFN $\alpha$ ) and interferon $\gamma$ (IFN $\gamma$ ), in a transient and dose-dependent manner. In this study, we used the same protocol to evaluate a formulated version of this extract, called Searup ${ }^{\circledR}$. Our experiments showed that a single oral administration of this product at the dose recommended for use in the farm, results in heterophils and monocytes activation. In heterophils, activation was evidenced by $\beta$-D-glucuronidase release and increased mRNA expression of IL1 $\beta$, IFN $\alpha$ and IFN $\gamma$. In monocytes, the expression of IFN $\gamma$ and inducible nitrite oxide synthase (iNOS) were also up-regulated. Finally, plasmatic NO increased significantly on day 1, decreased on day 2 and was no longer significant at day 3 . A similar pattern was observed for $\beta$-D-glucuronidase and for the modifications of the transcription profiles in monocytes as well as in heterophils. The only notable exception is gene transcription of 2'-5' Oligoadenylate Synthase, which is maximal at day 2 in monocytes. Due to its protective role in virus infection, this may constitute an additional layer of protection for this class of pathogens. Together our results show that the formulated solution, Searup ${ }^{\circledR}$, similarly to the purified extract allow to activate monocytes and heterophils but with some variations in the cytokines profiles and may provide protection against a larger variety of pathogens.

Keywords: Ulvans; Seaweed Polysaccharides; Avian; Monocytes; Heterophils

\section{Introduction}

Reducing antibiotic therapy and prophylaxis in livestock has become a priority over recent years. As a consequence, there has been intensive search for compounds able to activate innate immunity in livestock when given orally. This part of the immune system indeed provides a first defense line, able to recruit and drive the adaptive immune responses to pathogens. As in mammals, the Th1/ Th2 paradigm applies in chicken [1]. On the one hand, the Th1 response involves 


\section{Open Access Journal of Veterinary Science \& Research}

cellular immunity with cytotoxic lymphocytes, in response to intracellular pathogens and viruses and requires interferongamma (IFN $\gamma$ ) [1]. On the other hand, cytokines release for the Th2 response, especially interleukin 10 and 13 (IL10, IL13), in response to extracellular pathogens, including bacteria and viruses [1].

Seaweeds, red, green and brown, are an important source of bioactive compounds. Among them, sulfated polysaccharides like ulvans from green seaweed have been demonstrated to display biological properties [2].

We recently demonstrated that a purified ulvan extract activates chicken heterophils and monocytes through TLR2 and TLR4 receptors [3]. Herein we aimed at determining whether the Searup ${ }^{\circledR}$, a product where the ulvan extract is formulated with vitamins A and D3, shows similar properties on the immune stimulation of monocytes and heterophils in vivo.

\section{Methods}

\section{In vivo Experiments}

As previously described [3], 125 broilers (28 days old at day 0 of the trial) with a Ross 308 genetic background were dispatched in five experimental groups, given an increasing dose of the purified ulvan extract $(0,10,25,50 \mathrm{mg} / \mathrm{l})$, or the formulated version of the extract, called Searup ${ }^{\circledR}$ at $1 \mathrm{ml} / \mathrm{l}$, the recommended dose for use in the farm. Searup ${ }^{\circledR}$ contains ulvan extract and vitamins A and D3 according to the European legislation (EU 2015/724 and EU 2017/1492). Three repetitions of the experiments were performed in compliance with French laws and regulations and with the agreement of the Brest University ethics committee [3]. Animals were obtained from a local commercial hatchery and received the same diet and prophylaxis programs within and between the experiments [3].

\section{Cell Isolation and Plasma Samples Analysis}

As previously described and for ethical reasons, only $1 \mathrm{ml}$ of blood was taken from day 0 to day 3 for each animal [3]. Cell isolation was then realized on pooled blood samples from three chickens of the same group. Heterophils and monocytes were purified as previously described and frozen to allow RT-qPCR experiments $[3,4]$.

Heterophils degranulation was estimated by quantifying the $\beta$-D-glucuronidase activity in individual plasma. Beta-D-glucuronidase activity was calculated by measuring the fluorescence generated by cleavage of the 4 -methylumbelliferyl- $\beta$-D-glucuronide into fluorescent 4-methylumbelliferone. These values were converted to micromoles of 4-methylumbelliferone generated using a standard curve of known concentrations [3,5]. Nitrite oxide (NO) concentration was determined in triplicate with Griess' reagent using a standard nitrite concentration curve.

\section{RNA extraction, RT-qPCR}

The mRNA were extracted from purified cells using the RNeasy+ Mini Kit (Qiagen) and 200ng of total mRNA were reverse transcribed using the High-Capacity cDNA Reverse Transcription kit (Applied Biosystems). Quantitative PCR was performed using the Power SYBR Green PCR Master Mix (Applied Biosystems) using Actin as the internal control gene to normalize the analysis of expression of target gene. The results are expressed as the relative gene expression with the DeltaDeltaCt method. Fold change $=2^{-[(C t \text { target gene in sample-Ct }}$ actin in sample)-(Ct target gene in untreated cells-Ct actin in untreated cells)] [6]. Primer sequences are listed in table 1. Variations were considered as significant when fold changes reached at least two.

\begin{tabular}{|c|c|c|}
\hline Target & Sequence & Reference \\
\hline \multirow{2}{*}{$\beta$-actin } & F: 5'-CAACACAGTGCTGTCTGGTGGTA-3' & \multirow{12}{*}{ [7] } \\
\hline & R: 5'-ATCGTACTCCTGCTTGCTGATCC-3' & \\
\hline \multirow{2}{*}{ IL1 $\beta$} & F: 5'-GTGAGGCTCAACATTGCGCTGTA-3 & \\
\hline & R: 5'-TGTCCAGGCGGTAGAAGATGAAG-3' & \\
\hline \multirow{2}{*}{ IFN $\alpha$} & F: 5'-ATCCTGCTGCTCACGCTCCTTCT-3 & \\
\hline & R: 5'-GGTGTTGCTGGTGTCCAGGATG-3' & \\
\hline \multirow{2}{*}{$\operatorname{IFN} \beta$} & F: 5'-GCCTCCAGCTCCTTCAGAATACG-3' & \\
\hline & R: 5'-CTGGATCTGGTTGAGGAGGCTGT-3' & \\
\hline \multirow{2}{*}{ IFN $\gamma$} & F: 5'-ACACTGACAAGTCAAAGCCGCACA-3' & \\
\hline & R: 5'-AGTCGTTCATCGGGAGCTTGGC-3' & \\
\hline \multirow{2}{*}{ 2'-5' Oligoadenylate synthase (OAS) } & F:5'-AGAACTGCAGAAGAACTTTGTC-3' & \\
\hline & R:5'-GCTTCAACATCTCCTTGTACC-3' & \\
\hline
\end{tabular}




\section{Open Access Journal of Veterinary Science \& Research}

\begin{tabular}{|c|c|c|}
\hline \multirow{2}{*}{ IL8 } & F: 5'-CCAAGCACACCTCTCTTCCA-3' & \multirow{8}{*}{ [8] } \\
\hline & R: 5'-GCAAGGTAGGACGCTGGTAA-3' & \\
\hline \multirow{2}{*}{ IL10 } & F: 5'-AGCAGATCAAGGAGACGTTC-3' & \\
\hline & R: 5'-ATCAGCAGGTACTCCTCGAT-3' & \\
\hline \multirow{2}{*}{ IL13 } & F: 5'-ACTTGTCCAAGCTGAAGCTGTC-3' & \\
\hline & R: 5'-TCTTGCAGTCGGTCATGTTGTC-3' & \\
\hline \multirow{2}{*}{ iNOS } & F: 5' -GGCAGCAGCGTCTCTATGACTTG-3 ' & \\
\hline & R: 5'-GACTTTAGGCTGCCCAGGTTG-3' & \\
\hline \multirow{2}{*}{ TLR2 } & F: 5'- ATCCTGCTGGAGCCCATTCAGAG-3' & \multirow{6}{*}{ [9] } \\
\hline & R: 5'- TTGCTCTTCATCAGGAGGCCACTC-3' & \\
\hline \multirow{2}{*}{ TLR4 } & F: 5'- TGCCATCCCAACCCAACCACAG-3' & \\
\hline & R: 5'- ACACCCACTGAGCAGCACCAA-3' & \\
\hline \multirow{2}{*}{ IL17 } & F: 5'CACTGCTGTTGGTGTTGCT-3' & \\
\hline & R:5'TCAGCAACCAAGCGGGGG-3 & \\
\hline \multirow{2}{*}{ IL18 } & F: 5'-GGA ATG CGA TGC CTT TTG3' & \multirow{2}{*}{ [10] } \\
\hline & R :5’ ATT TTC CCA TGC TCT TTC TCA3' & \\
\hline
\end{tabular}

Table 1: Primers sequences.

\section{Statistical Analysis}

Comparisons between groups were performed using ANOVA1 test and Bonferroni correction with the PRISM Software. Values are given as mean \pm SEM. P values $<0.05$ were considered significant.

\section{Results}

\section{Monocytes Response to Searup ${ }^{\circledR}$}

A single administration of the formulated version of the ulvan extract elicited NO secretion in a time-dependent manner similarly to the algal extract (Figure 1). NO concentrations rose to $36.60 \pm 1.61 \mu \mathrm{M}$ on day $1,31.10 \pm$ $1.03 \mu \mathrm{M}$ on day 2 before declining to $11.73 \pm 0.36 \mu \mathrm{M}$ on day 3 . This is in line with the mRNA expression of the iNOS gene

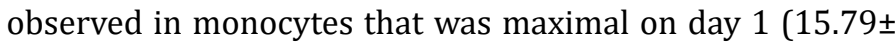
1.49) before decreasing to $7.22 \pm 0.45$ on day 2 and to a nearly

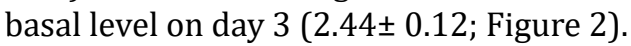

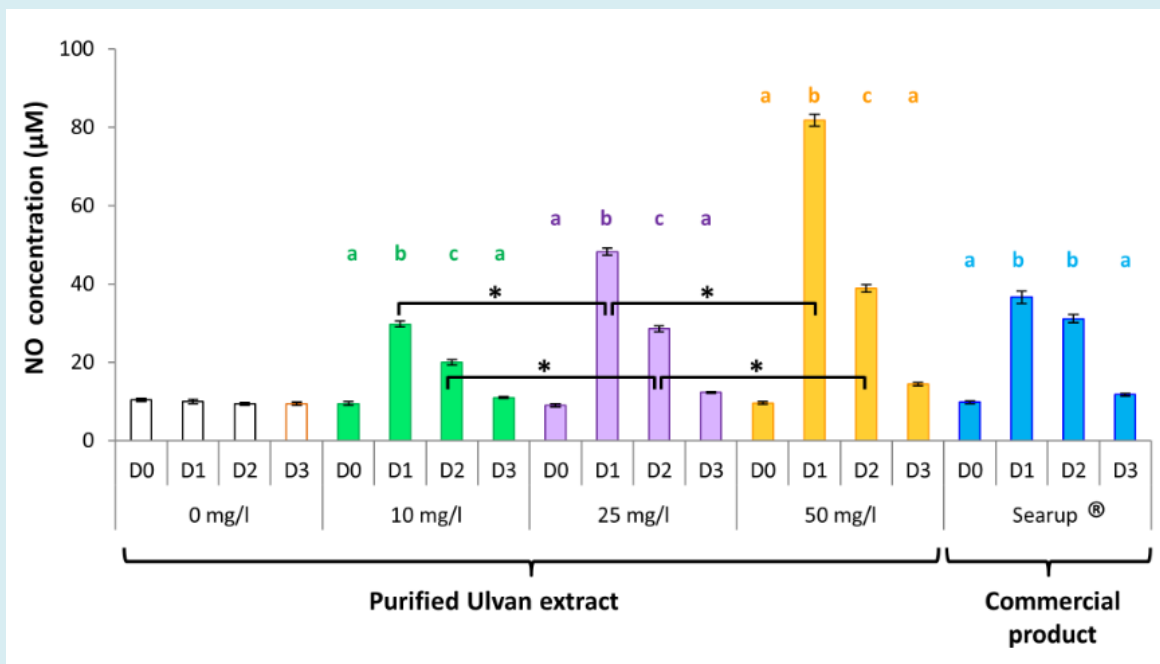

Figure 1: Ulvan activates monocytes in vivo when given orally.

Data represents the mean \pm SEM, of control group and treated group analyzed from day 0 to day 3 . The samples of three animals were pooled for purification and RT-qPCR. Different letters with the same color indicate statistically different values for the different doses at the same time with $\mathrm{p}<0.05\left(^{*}\right)$. 


\section{Open Access Journal of Veterinary Science \& Research}

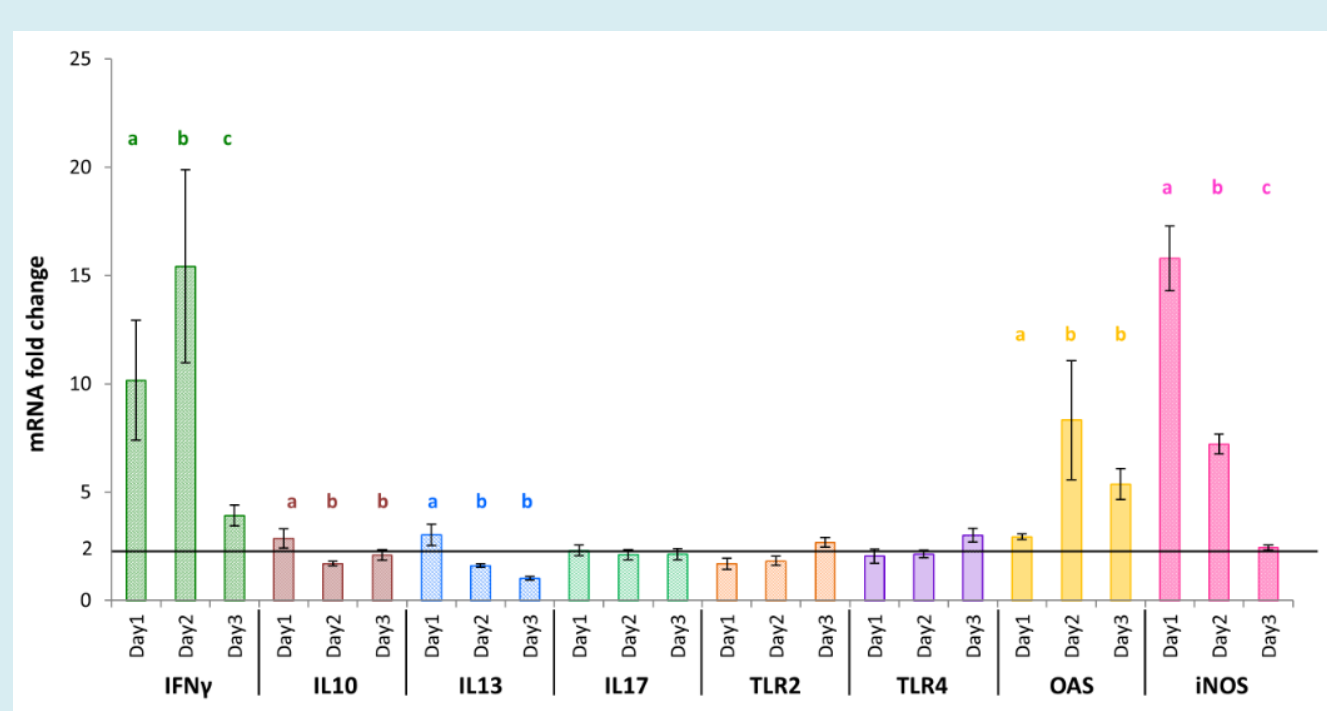

Figure 2: Modified monocytes cytokine transcription pattern in response to a formulated Ulvan version (Searup ${ }^{\circ}$ ). Data represents the mean \pm SEM, of control group and treated group analyzed from day 0 to day 3 . The samples of three animals were pooled for purification and RT-qPCR. Different letters with the same color indicate statistically different values for the different doses at the same time with $\mathrm{p}<0.05\left(^{*}\right)$.

In addition, the amount of IFN $\gamma$ mRNA that was also high on day $1(10.17 \pm 2.86)$, increased further on day 2 (15.43 \pm 4.44) and then decreased to $3.93 \pm 0.47$ on day 3 (Figure 2). The OAS gene expression was also modified in chicken who received the Searup ${ }^{\circledR}$ with a fold change of $2.94 \pm 0.12$ on day $1,8.33 \pm 2.75$ on day 2 , and $5.37 \pm 0.72$ on day 3 (Figure
2). The IL10, IL13, TLR2, TLR4 mRNA expression were moderately impacted with variations below $3.02 \pm 0.49$, the highest value which was obtained at day 1 for IL13 (Figure 2). Also, IL1 $\beta$, IL17, IFN $\alpha$, IFN $\beta$, IL18, and IL8 mRNA level did not differ from the untreated animal group at any time points (Table 2).

\begin{tabular}{|c|c|c|c|c|c|}
\hline \multicolumn{7}{|c|}{ Day 1, fold changes, monocytes } \\
\hline & IL1 $\beta$ & IFN $\alpha$ & IFN $\beta$ & IL18 & IL8 \\
\hline Control & $0.95 \pm 0.07$ & $1.03 \pm 0.09$ & $1.05 \pm 0.10$ & $1.03 \pm 0.07$ & $1.05 \pm 0.09$ \\
\hline Searup ${ }^{\circledR} 1 \mathrm{ml} / \mathrm{I}$ & $1.42 \pm 0.23$ & $1.70 \pm 0.20$ & $1.21 \pm 0.18$ & $1.12 \pm 0.09$ & $1.52 \pm 0.36$ \\
\hline \multicolumn{7}{|c|}{ Day 2, fold changes, monocytes } \\
\hline \multicolumn{7}{|c|}{ IL1 $\beta$} & IFN $\alpha$ & IFN $\beta$ & IL18 & IL8 \\
\hline Control & $1.05 \pm 0.09$ & $1.00 \pm 0.09$ & $1.15 \pm 0.10$ & $1.05 \pm 0.08$ & $1.06 \pm 0.12$ \\
\hline Searup $1 \mathrm{ml} / \mathrm{l}$ & $0.96 \pm 0.07$ & $1.04 \pm 0.10$ & $1.02 \pm 0.18$ & $2.04 \pm 0.27$ & $1.14 \pm 0.11$ \\
\hline \multicolumn{7}{|c|}{ Day 3, fold changes, monocytes } \\
\hline \multicolumn{7}{|c|}{} & IFN $\alpha$ & IFN $\beta$ & IL18 & IL8 \\
\hline Control & $1.04 \pm 0.09$ & $1.00 \pm 0.09$ & $1.07 \pm 0.11$ & $0.99 \pm 0.08$ & $1.06 \pm 0.07$ \\
\hline Searup $1 \mathrm{ml} / \mathrm{l}$ & $1.08 \pm 0.13$ & $1.07 \pm 0.11$ & $1.05 \pm 0.11$ & $1.98 \pm 0.25$ & $1.00 \pm 0.12$ \\
\hline
\end{tabular}

Table 2: Cytokines genes not statistically modified in monocytes in vivo when the formulated version of the ulvan extract (Searup ${ }^{\circ}$ ) is given orally.

Data represents the mean \pm SEM of control group and treated group analyzed from day 0 to day 3 . The samples of three animals were pooled for purification and RT-qPCR.

\section{Searup $^{\circledR}$ Induces Heterophils Activation}

Another leading cell type in innate immunity is the heterophil, partly due to its ability to release $\beta$-D- glucuronidase upon activation [8]. Activation was shown to occur in a time-dependent manner following the $24 \mathrm{~h}$ Searup ${ }^{\circledR}$ application with a maximal activity on day 1 with 4-methylum-belliferone concentrations of $46.57 \pm 1.14 \mu \mathrm{M}$, 


\section{Open Access Journal of Veterinary Science \& Research}

before declining to $15.75 \pm 0.61 \mu \mathrm{M}$ on day 2 and returning to baseline concentrations of $6.23 \pm 0.08 \mu \mathrm{M}$ on day 3 (Figure 3).

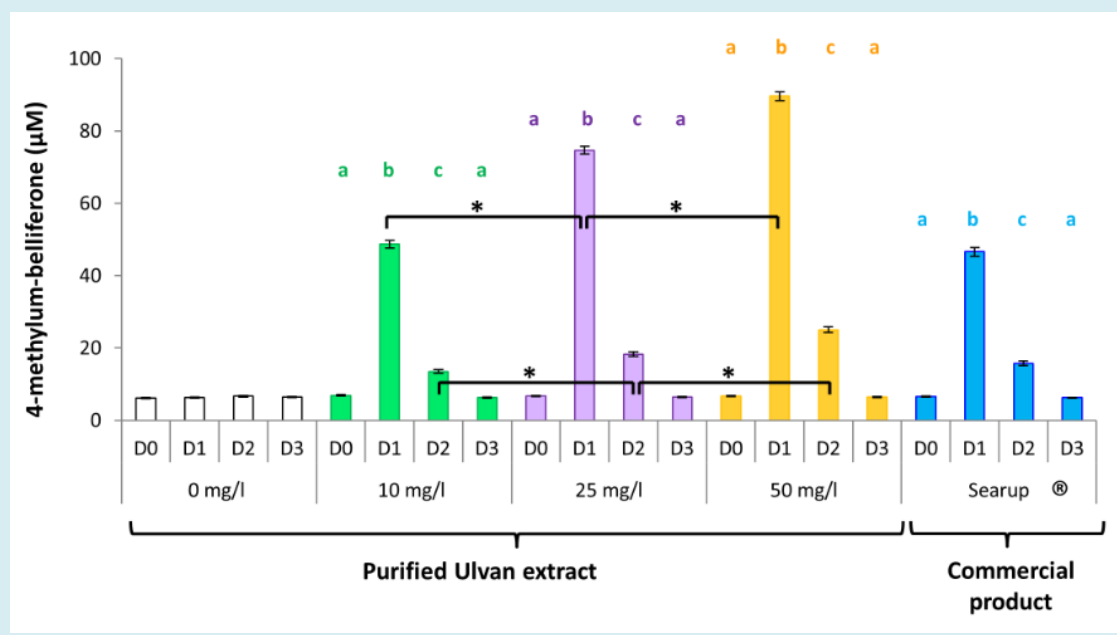

Figure 3: Ulvan activates heterophils in vivo when given orally.

Data represents the mean \pm SEM, of control group and treated group analyzed from day 0 to day 3 . The samples of three animals were pooled for purification and RT-qPCR. Different letters with the same color indicate statistically different values for the different doses at the same time with $\mathrm{p}<0.05\left(^{*}\right)$.

Furthermore, heterophils' activation resulted in a similar expression profile for IL1 $\beta$ and IFN $\alpha$ mRNA that are $17.34 \pm 1.95$ and $21.00 \pm 1.93$-fold upregulated at day 1 post treatment respectively (Figure 4 ). Then we observed a strong decrease of expression at day $2(7.50 \pm 1.18$ and $8.04 \pm 0.58)$ that carried on at day 3. In parallel, the mRNA expression of IFN $\gamma$, IL10, IL13, IL17 and OAS increased significantly with maximal levels on day 2, before decreasing at day 3 . The most significant variations in this group was shown for the
IFN $\gamma$ gene which was about 16 and 21-fold more expressed than in the non-treated group on day 1 and 2 respectively. Finally, IL8, TLR2 and TLR4 mRNA showed a more moderate regulation of expression in chickens who received Searup ${ }^{\circledR}$, nevertheless we could observe a statistically significant increase on day 1 , which remains on day 2 before decreasing on day 3. No significant variations were observed for IFN $\beta$ and IL18 genes (Table 3).

\begin{tabular}{|c|c|c|}
\hline \multicolumn{3}{|c|}{ Day 1, fold changes, heterophils } \\
\hline & IL18 & IFN- $\beta$ \\
\hline Control & $1.09 \pm 0.22$ & $1.03 \pm 0.34$ \\
\hline Searup $₫ 1 \mathrm{ml} / \mathrm{l}$ & $1.15 \pm 0.08$ & $1.43 \pm 0.25$ \\
\hline & Day 2, fold changes, heterophils & IFN- $\beta$ \\
\hline & IL18 & $0.92 \pm 0.12$ \\
\hline Control & $1.17 \pm 0.23$ & $1.06 \pm 0.19$ \\
\hline Searup $₫ 1 \mathrm{ml} / \mathrm{l}$ & $1.75 \pm 0.14$ & IFN- $\beta$ \\
\hline & Day 3, fold changes, heterophils & $1.05 \pm 0.34$ \\
\hline Control & IL18 & $0.98 \pm 0.25$ \\
\hline Searup
\end{tabular}

Table 3: Cytokines genes not statistically modified in heterophils in vivo when the formulated version of the ulvan extract (Searup $)$ is given orally.

Data represents the mean \pm SEM, of control group and treated group analyzed from day 0 to day 3 . The samples of three animals were pooled for purification and RT-qPCR. 


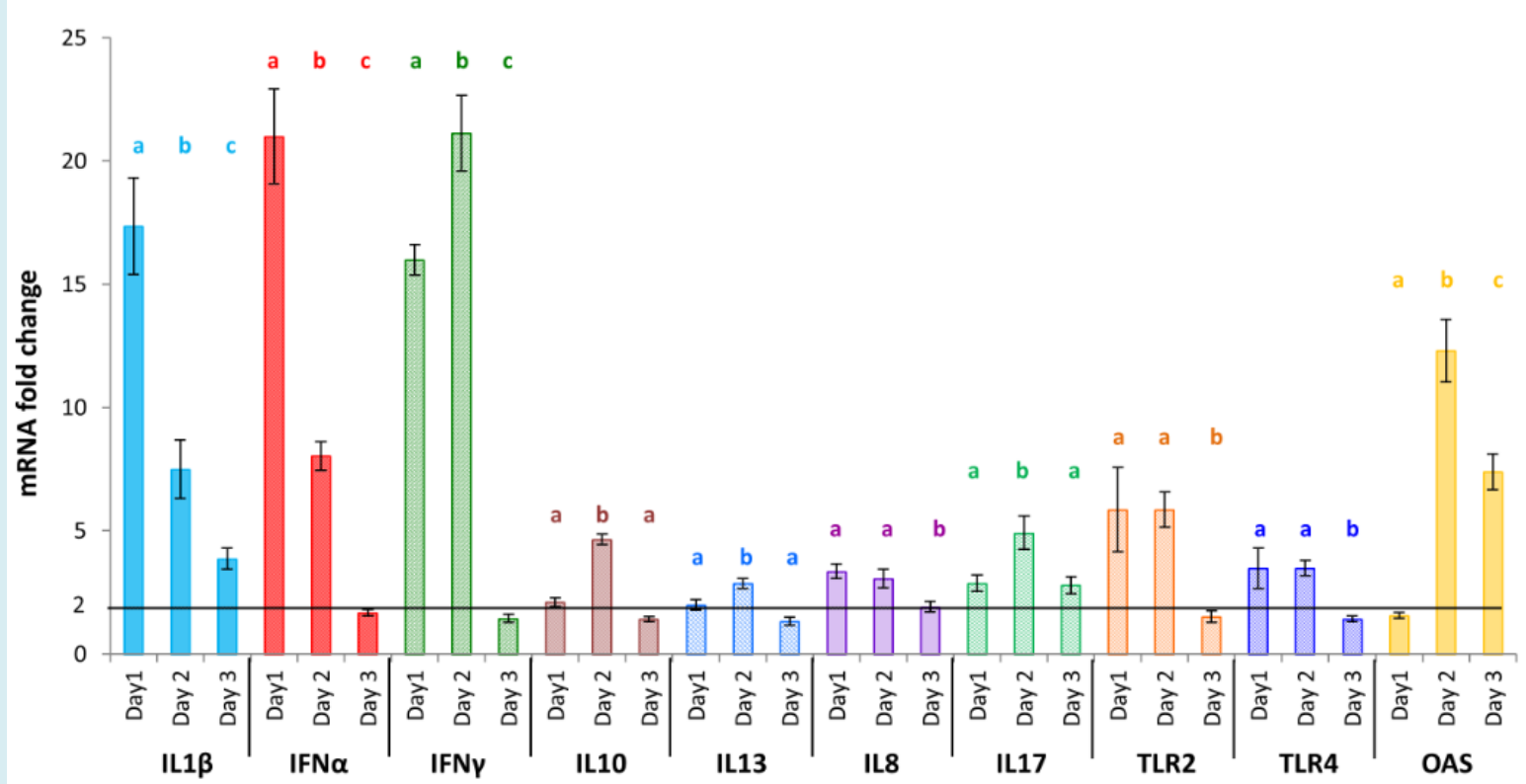

Figure 4: Modified heterophils cytokine transcription pattern in response to a formulated Ulvan version (Searup ${ }^{\circ}$. Data represents the mean \pm SEM, of control group and treated group analyzed from day 0 to day 3 . The samples of three animals were pooled for purification and RT-qPCR. Different letters with the same color indicate statistically different values for the different doses at the same time with $\mathrm{p}<0.05\left(^{*}\right)$.

\section{Discussion}

In a previous study, it was shown that a purified ulvan extract activates chicken monocytes and heterophils when given orally at dosage between 10 and $50 \mu \mathrm{g} / \mathrm{ml}$ [3].

In this work, we show that Searup ${ }^{\circledR}$, the formulated version of the ulvan extract, given as a single administration at $1 \mathrm{ml} / \mathrm{l}$ of drinking water, the specific dose for use in the farm, is sufficient to induce a transient activation heterophils and monocytes in a transitory manner. The amount of Ulvan administrated via this dosage enters in the concentration range used in Guriec, et al. [3].

To be noted, our results indicate that the vitamins $A$ and D3 contained in Searup ${ }^{\circledR}$ do not affect the ability of the ulvan extract to modulate the activation of these immune cells. In addition, vitamins A and D3 act via transcription factors with an action time around $72 \mathrm{~h}$, due to the time needed for absorption, transport to the cells, transcription of mRNA, translation into proteins and post-translational modifications [11]. The current study only analyzes the effects from 0 to $72 \mathrm{~h}$ that can thus be attributed to the ulvan extract.

The release of Nitrite Oxide and $\beta$-D-glucuronidase in plasmas show a peak of production on day 1 with Searup ${ }^{\circledR}$ in agreement with our previous work with the ulvan extract [3]. Nitrite Oxide synthesis reflects, mainly, monocytes' activation as avian heterophils do not synthetize significant amount of NO due to the lack of myeloperoxidase [12]. In accordance with the plasma concentration of NO, the iNOS gene is shown to be transiently more transcribed in monocytes with a maximal increase on day 1 . Furthermore, $\beta$-D-glucuronidase is released upon heterophils' activation and contributes to protection against virus and bacteria [1214]. Protection against viruses is also the task of OAS, via the cleavage of viral RNA transcripts and host RNAs [15]. The OAS gene is induced with similar time courses by the purified extract and its formulated version, in heterophils as well as in monocytes, with a maximal transcription on day 2 . This transitory transcription pattern is observed for all genes activated and with a decrease on day 3 , except for TLR2 and TLR4 in monocytes where a slight increase is observed on day 3. These receptors also seem to be slightly more expressed in heterophils than in monocytes, in agreement with our previous results [3].

With the purified extract, IFN $\gamma$ show a peak of transcription day 1, in monocytes and heterophils [3], while with the formulated version a significant increase in transcription is observed on day 1 but the peak is reached only on day 2 . In our previous work, we demonstrated that the increase in transcription is associated with an increase of IFN $\gamma$ protein in plasma and thus may improve protection against pathogens. Chicken IFN $\gamma$ has indeed been demonstrated to act similarly to its mammalian counterparts 


\section{Open Access Journal of Veterinary Science \& Research}

and to induce of MHC class I and class II [15]. In addition, chicken IFN $\gamma$ also tightly regulates the production of NO [15] and anti-viral activity against vesicular stomatitis virus, infectious bursal disease virus, Newcastle disease virus $[16,17]$.

Furthermore, similarly to the purified ulvan extract, IFN $\alpha$ mRNA is more transcribed in the heterophils of animals that received the formulated version of the ulvan extract with a similar transcription pattern and time course [3]. Heterophil stimulation leads to IFN $\alpha$ transcription, as in viral immune response, for example during influenza A virus and Newcastle disease virus infection [15].

However, IL10, IL13, IL17 are more expressed in heterophils and monocytes with the formulated extract. The differences in gene expression are however limited, which raises the question of the impact on their protein concentrations in plasmas, as variation on the protein level are often lower than that of the gene expression.

\section{Conclusion}

In conclusion, a unique administration of Searup ${ }^{\circledR}$ at $1 \mathrm{ml} / \mathrm{l}$, dose recommended for use in the farm, is able to activate chicken heterophils and monocytes, and potentially to mount a strong immune response that could help to control pathogens. Moreover, the stimulated cytokine genes belong to the Th1, Th2 and Th17 pathways, suggesting that they might support all these orientations for an acquired immune response. These may be further complemented by the vitamin effects appearing only $72 \mathrm{~h}$ and onwards.

\section{Acknowledgement}

The authors would like to acknowledge the ORPHY team (Christine Moisan, Marie-Agnes Giroux-Metges) for their support.

\section{Funding}

This work was financed by a grant from the BPI-France/ ISI Ulvans project ( $\mathrm{n}^{\circ}: \mathrm{I} 1110001 \mathrm{~W}$ ) to Amadéite company, Bréhan (France), a project certified by Pôle Mer Bretagne.

\section{Competing Interests}

Authors Frédérick Bussy, Christelle Gouin, Matthieu Le Goff, Pi Nyvall Collén were employed by company Amadéite, now Olmix SA. The remaining authors declare that the research was conducted in the absence of any commercial or financial relationships that could be construed as a potential conflict of interest.

\section{References}

1. Lowenthal JW, Bean AGD, Kogut MH (2013) What's so special about chicken immunology? Dev Comp Immunol 41(3): 307-309.

2. Xu SY, Huang X, Cheong KL (2017) Recent advances in marine algae polysaccharides: Isolation, structure, and activities. Mar Drugs 15(12): 388-404.

3. Guriec N, Bussy F, Gouin C, Mathiaud O, Nyvall Collèn P, et al. (2018) Ulvan Activates Chicken Heterophils and Monocytes Through Toll-Like Receptor 2 and Toll-Like Receptor 4. Front Immunol 9: 2725-2744.

4. Farnell MB, Crippen TL, He H, Swaggerty CL, Kogut MH (2003) Oxidative burst mediated by toll like receptors (TLR) and CD14 on avian heterophils stimulated with bacterial toll agonists Dev Comp Immunol 27(5): 423429.

5. Kogut MH, Genovese KJ, Lowry VK (2001) Differential activation of signal transduction pathways mediating phagocytosis, oxidative burst, and degranulation by chicken heterophils in response to stimulation with opsonized Salmonella enteritidis Inflammation 25(1): 7-15.

6. Livak KJ, Schmittgen TD (2001) Analysis of relative gene expression data using real-time quantitative PCR and the 2(-Delta Delta C(T)) Method Methods 25(4): 402-428.

7. Barjesteh N, Behboudi S, Brisbin JT, Villanueva AI, Nagy E, et al. (2014) TLR Ligands Induce Antiviral Responses in Chicken Macrophages PloSOne 9: e105713.

8. St. Paul M, Mallick AI, Haqa K, Oroujia S, Abdul-Careemb $\mathrm{MF}$, et al. (2011) In vivo administration of ligands for chicken toll-like receptors 4 and 21 induces the expression of immune system genes in the spleen Vet Immunol Immunopath 144(3-4): 228-237.

9. St Paul M, Barjesteh N, Paolucci S, Pei Y, Sharif S (2012) Toll-like receptor ligands induce the expression of interferon-gamma and interleukin-17 in chicken CD4+ T cells BMC Res Notes 5: 616.

10. Mucksová J, Plachý J, Staněk O, Hejnar J, Kalina, J, et al. (2017) Cytokine response to the RSV antigen delivered by dendritic cell-directed vaccination in congenic chicken lines Vet Res 48: 18.

11. Wintergerst ES, Maggini S, Hornig DH (2007) Contribution of selected vitamins and trace elements to immune function Ann Nutr Metab 51(4): 301-23. 


\section{Open Access Journal of Veterinary Science \& Research}

12. Genovese KJ, He H, Swaggerty CL, Kogut MH (2013) The avian heterophil Dev Comp Immunol 41(3): 334-340.

13. Van Dijk A, Veldhuizen EJA, Haagsman HP (2008) Avian defensins Vet Immunol Immunopathol 124(1-2): 1-18.

14. Van Dijk A, Tersteeg-Zijderveld MHG, Tjeerdsma-van Bokhoven JLM, Jansman AJM (2009) Chicken heterophils are recruited to the site of Salmonella infection and release antibacterial mature Cathelicidin-2 upon stimulation with LPS Mol Immunol 46(7): 1517-1526.

15. Goossens K, Ward AC, Lowenthal JW, Bean AGD (2013)
Chicken interferons, their receptors and interferonstimulated genes Dev Comp Immunol 41(3): 370-376.

16. Mallick AI, Haq K, Brisbin JT, Mian MF, Kulkarni RR, et al. (2011) Assessment of bioactivity of a recombinant chicken interferon-gamma expressed using a baculovirus expression system J Interf Cyt Res 31(6): 493-500.

17. Lambrecht B, Gonze M, Morales D, Meulemans G, van den Berg TP (1999) Comparison of biological activities of natural and recombinant chicken interferon-gamma Vet Immunol Immunopathol 70(3-4): 257-267. 